Article

\title{
Conceptual Framework for the Research on Quality of Life
}

\author{
José Rodrigues $1,2, * \mathbb{C}$, Carla Chicau Borrego ${ }^{1,2}$, Paula Ruivo ${ }^{1,3}$, Pedro Sobreiro ${ }^{1,2} \mathbb{C}_{\text {, }}$ \\ David Catela ${ }^{1,2}$, José Amendoeira ${ }^{1,4}$ and Rui Matos ${ }^{1,5}$ \\ 1 Life Quality Research Centre (CIEQV), IPSantarém/IPLeiria, 2040-413 Rio Maior, Portugal; \\ ccborrego@esdrm.ipsantarem.pt (C.C.B.); paula.ruivo@esa.ipsantarem.pt (P.R.); \\ sobreiro@esdrm.ipsantarem.pt (P.S.); catela@esdrm.ipsantarem.pt (D.C.); \\ jose.amendoeira@essaude.ipsantarem.pt (J.A.); rui.matos@ipleiria.pt (R.M.) \\ 2 Sport Sciences School of Rio Maior, Polytechnic Institute of Santarém, 2040-413 Rio Maior, Portugal \\ 3 School of Agriculture of Santarém, Polytechnic Institute of Santarém, 2001-904 Santarém, Portugal \\ 4 Health School of Santarém, Polytechnic Institute of Santarém, 2005-075 Santarém, Portugal \\ 5 School of Education and Social Sciences, Polytechnic Institute of Leiria, 2411-901 Leiria, Portugal \\ * Correspondence: jrodrigues@esdrm.ipsantarem.pt; Tel.: +31-59-6170-0838
}

Received: 12 May 2020; Accepted: 12 June 2020; Published: 16 June 2020

check for updates

\begin{abstract}
The article presents the reference framework for multidisciplinary research at the Life Quality Research Centre (LQRC). The research paradigm about the citizens' quality of life in society imposes a multifaceted and complex analysis. At the LQRC we address this as thematically divided into six scientific areas: education and training; physical activity and healthy lifestyles; food production and technology on food behaviors; organizational dynamics; motor behavior; and individual and community health. These areas are clearly related to the concept of quality of life. They fit the goals and dynamics of the research center. In each section, the authors develop the themes of research projects and the challenges that characterize research in the area of quality of life. It is clear that there is an agreement and understanding that ensures that quality of life research is on the agenda of the world organizations related to scientific research and human development. This is a real challenge for scientific research centers, since multidisciplinary paradigms are the foundation of our collective organization, and the evolution of research on quality of life could fulfil current needs and lead to the improvement of citizen lives.
\end{abstract}

Keywords: quality of life; multidisciplinary research; education; physical activity and sport; health; food behaviors; organizations; creativity

\section{Introduction}

Research on citizens' quality of life is a cross-cutting, multidisciplinary, and fundamental issue concerning current society. The purpose of contemporary societies focuses on the physical, psychological, and social well-being of the population, translated into a set of policies and actions that aim to contribute to this endeavor. The present scope is at the heart of our reflection, in which we seek to explore and develop the conceptual framework associated with the idea of quality of life.

The authors present detailed concerns in the dimensions that constitute the scientific areas of research at the Life Quality Research Centre. Specifically, the authors intend to explore an approach for dealing with the concept of quality of life, developing the implications that physical activity, movement, food, education, organizations, and health can have in the production and diffusion of applied research. We propose a strategy centered on these six areas as they are those that best fit the characteristics of the center and the consortium of institutions that support it. For example, we have little focus on issues of economic well-being which is an important area in subjective indicators and quality of life objectives. 
This conceptual framework supports the research activity of the Life Quality Research Centre (LQRC), to which the authors are affiliated, considering the research outcomes (academic and applied) to individual and team research projects produced at the research center. This research center is accredited by the Portuguese agency for scientific research. It is a unit with eighty researchers from different areas involved in research on quality of life. The center is managed under a consortium between two higher education institutions, namely the Polytechnic Institute of Santarem and the Polytechnic Institute of Leiria, both located in the central western regions of Portugal.

The mission of the LQRC is to contribute to the production of knowledge and innovation, as well as to the promotion of improving the quality of life for human beings. The center initially started by developing projects in each one of its areas of common interest. However, it became clear that the operational work resulting from the interconnection of the different lines of research would provide greater and better results concerning the assessment of quality of life. The multidisciplinary nature of the center is one of its greatest assets and one of its greatest challenges is bringing together researchers from different areas. Combining its areas seems paramount for understanding how society endorses behaviors related to quality of life. Therefore, this center intends to promote research on quality of life using an innovative framework of scientific multidisciplinary, interdisciplinary, and transdisciplinary relationships among different but complementary areas.

The authors understand by quality of life the value that each citizen gives to their social and individual status, in a society in which people relate and interact in order to satisfy their ambitions, needs, and expectations. This notion is based on the concept that global organizations influence citizens' health determinants, as proposed by the World Health Organization (WHO). The approach is multifaceted and complex, requiring multidisciplinary and integrated scientific analysis, aiming to improve the population's life conditions in the social, psychological, and physical dimensions [1].

The literature presents several studies on quality of life examining variables and determinants of great social and scientific relevance. However, there are different approaches focusing on several sectoral perspectives and with unique conceptual frameworks, making it difficult to assess quality of life. According to Pereira and colleagues [2], the concept of quality of life has different individual meanings, which makes its evaluation and scientific investigation difficult to determine. It seems that there is a need to increase multidisciplinary research and intervention studies to improve the quality of life of citizens.

This need for multidisciplinary scientific research is embraced by the center as a fundamental challenge. Treating quality of life as a complex interdisciplinary and social concept allows the center to stipulate its ambition for relevant and impactful scientific production for society's development and sustainability.

LQRC's activity is based on scientific production in three strategic vectors for research, namely: i) education, in the domains of development of students in social, psychomotor, and cognitive perspectives, in the quest for health-related habit formation; ii) physical activity, embracing several biological, psychological, and social indicators, aiming to study the relationship between citizens and healthy lifestyles; and iii) food, dealing with food production and technology, as well as eating behaviors, providing fundamental knowledge for the quality of life of citizens. The research that is developed in the LQRC contributes to knowledge about the quality of life in organizations and about individual and community health.

The center incorporates researchers from several higher education institutions so that scientific production on quality of life will have an exponential effect on its institutions and society itself, since institutions are dedicated to the training of professionals who will work in the already covered strategic sectors. It can be said that the multidisciplinary knowledge that is produced by LQRC researchers favors the content updating of the higher education training programs in the institutions to which researchers are associated. On the other hand, the center has a beneficial impact on researcher and teacher training programs assessing the second- and third-cycle education programs in higher education to be of quality. Hence, it is important to identify the main scientific areas in which the center 
operates and the mission to produce research on quality of life. The authors will explore each of the six LQRC scientific areas: i) education and training; ii) physical activity and healthy lifestyles; iii) food production and technology on food behaviors; iv) organizational dynamics; v) motor behavior; and vi) individual and community health. Academics and professionals-developing a transdisciplinary perspective to promote the capacity of individual and community to understand the relevance of physical activity, good nutrition, education, organization, motor behavior and health—gain experience in emphasizing in a healthy way the multidisciplinary approach to quality of life.

\section{Education and Training}

Quality of life is a concept of which all individuals seem to know the meaning but are unable to specifically define it. One aspect that contributes to this struggle arises from the fact that it is anchored in multiple aspects of individual lives such as health, personal safety, and leisure, as well as in other health-related factors.

The World Health Organization, through its WHOQOL group [3], has defined quality of life as the "individual's perception of their position in life in the context of the culture and value systems in which they live and in relation to their goals, expectations, standards and concerns" (p. 1405), comprising six broad domains: physical health, psychological health, level of independence, social relations, environment, and spirituality/religion/personal beliefs. WHO has developed its own instruments for measuring quality of life aspects (i.e., WHOQOL-100 and the WHOQOL-BREF).

As stated in previous literature, education is an indicator included in several indexes of quality of life; for instance, the Human Development Index [4], the International Living Index, and the Swedish ULF system [5]. Thus, education is directly or indirectly rendered as one of the fundamental pillars of quality of live. The authors agree that education is a worthy area of research as that reflects its broad application in different areas, such as quality of life research.

Additionally, in accordance with previously mentioned conceptualization, research on education examines educational patterns and learning processes and their different outcomes. It seeks to describe, understand, and explain how and why learning takes place throughout a person's life. Thus, we propose a two-fold approach when assessing the relationship between education and quality of life: (i) to discuss research related to these two concepts; and (ii) to propose and explore research topics on education for enhancing quality of life.

Looking at the first approach, the final report of the expert group on quality of life indicators [6] is quite impressive and revealing. Besides the clear link between education and people's income, it still matters for quality of life independent of this effect. Education also empowers individuals through a broad range of skills, habits, values and attitudes. Not surprisingly, the United Nations 2030 Agenda and its 17 goals for sustainable development include education (at number 4), aiming to ensure inclusive and equitable quality education and to promote lifelong learning opportunities for all human beings. The literature suggests that inadequate health literacy negatively affects quality of life [7-9]. Specifically, education can play a key role since more educated people engage in healthier lifestyles, suggesting a greater quality of life. A recent study [10] which considered a sample of nearly 9000 adults (in poor and in good health) from 13 countries also found that quality of life (measured using the WHOQOL-BREF) was greater in more educated individuals compared to those with less education. Thus, it is possible to assume that there is a clear and paramount association between education and quality of life that should be explored in detail.

Concerning the second approach, the authors propose three complementary vectors related to the education research and quality of life: i) new teaching/training methods; ii) behavioral change techniques education; and iii) contribution of formal and informal contexts of education to learning and development. The authors will develop each vector in more detail.

New teaching/training methods such as flipped classroom, design thinking, and project-based learning are becoming quite popular nowadays. The flipped classroom learning model enables a more effective practice and interactions, both among teachers and students, by inversion of in-class and home 
activities. Free from having to spend class time on transmitting knowledge to students, the teacher may engage in learning activities such as discussion and helping students with problem-solving [11,12]. At its origin, design thinking was focused on commercial and social problem-solving. Applied to teaching, it drives students through several stages, seeking their creativity and encouraging a hands-on approach. Through convergent and divergent procedures, students reach the point of proposing solutions for the problems they began dealing with. Similarly to the flipped classroom approach, students assume a central role in the teaching-learning process, which deepens their discussions for a more favorable atmosphere for teaching; as they are more active, students become more attentive in class and performance improves $[13,14]$. Finally, project-based learning, quite similarly to the previous methods, starts from the premise of centering the education process on students. It aims at promoting critical thinking and problem-solving in learning situations, requiring an interdisciplinary approach. This seems to enhance students' motivation since they deal with a more global, not fractioned, reality $[15,16]$.

The recent COVID-19 pandemic has also led to more education based on online learning methods when physical presence is not possible. Even though online learning had already existed in the past, now it has become a widespread method for education and teachers and researchers have had to adjust their workforce towards online teaching. Besides, researchers are conducting a survey to understand if people are willing to return to physical exercise and sport in closed sports facilities, complemented with proposals of doing some of the tasks in another way, with contributions from the areas of healthy lifestyle, physical activity and education. At the same time, an international study (in process, with LQRC participation) with more than 2000 children (up to 12 years of age), being conducted in Spain, Portugal and several Latin American countries, is trying to detect how habits change, namely regarding physical activity, feeding, and sleeping. As a final example of how we are aware of and handling the implications of COVID-19, other studies conducted by LQRC are aiming to detect important health issues, both physical and mental, occurring during the pandemic due to difficulties in maintaining healthy lifestyles within this period.

Education plays a key role when it comes to behavioral change. For instance, change is a key factor whether a person is seeking a healthier lifestyle or enhanced motor behavior. Just as an example, the Fun Theory has shown the potential that changing the environment has on behavioral change, whenever people understand or feel that changing the behavior leads to enhanced pleasure and well-being. Its application in a Swedish metro station (musical stairs) a few years ago is a well-known event, in which people began using the regular stairs much more instead of escalators. Using fun as an educational tool is something that deserves our attention, namely when talking about gamification. Research has shown that gamification, the use of game design elements in a non-gaming context, can, for instance, increase physical activity levels $[17,18]$. Thus, behavioral change techniques in education should be considered when training and teaching future professionals.

Finally, looking at the contribution of formal and informal contexts of education to learning and development, education features as an important factor in different contexts and domains. Aside from the most obvious one of school education, more research is needed to reveal the contribution that sport clubs, music associations, recreational organizations, and scout groups may have on learning and development processes. By doing this research, we will have a clearer view of how these different contexts can act in promoting more efficient education, and, thus, better quality of life in every student.

\section{Physical Activity and Healthy Lifestyles}

Within a socio-ecological approach, the research area of physical activity and healthy lifestyle aims to contribute to a multidimensional understanding of the functional, recreational, health-related, and performance-related outcomes of health-related behaviors. According to this model, sport participation is multidimensional in its nature and operates across individual, interpersonal, community, and societal levels. As it is well-established in the literature, physical activity has a great impact on improving health, quality of life, overall well-being, as well as on reducing health care costs. These improvements can benefit school performance as well as reduce the risk of at least 20 chronic diseases and conditions 
and provide effective treatment for many of these conditions. A recent meta-analysis showed that sustained engagement in exercise can reduce all-cause mortality by up to $33 \%[19,20]$.

Other international associations, such as the New Health Foundation and the project 'Lifestyle is medicine' (https://new-health.eu/en), have also been aiming at promoting physical activity behaviors. The project is putting effort in providing sports and lifestyle organizations, professionals, volunteers, and consumers with knowledge that is easy to obtain and understand and tools to improve physical activity. Additionally, this project strongly believes in healthier generations, fighting against the use of doping, and developing educational standards for healthy lifestyles.

The sport and fitness professionals are also crucial agents for promoting health-related behaviors and for changing sedentary and physically inactive behaviors into active lifestyles. Thus, it seems to be of public interest to research the impact of interpersonal behaviors induced by sport and fitness professionals and how it is related to the quality of the life of individuals living in the community (e.g., Life for fitness professional) [21,22].

Health-related information is associated with life stages, life events and experiences. Therefore, childhood and adolescence are crucial periods for investments in future public health, since they concern the potential for healthy adolescents now, for the adults they become, and for future generations [23].

Despite the widely acknowledged benefits of physical activity in social and individual domains, sedentary children and youths have also been well-documented, as physical inactivity in these developmental stages is a growing concern among countries. As such, contemporary practitioners and researchers have aimed at investigating the facilitators and barriers that increase or reduce the likelihood of participation in sport and physical activities [24-26].

Almost all forms of programed leisure-time sport and exercise have been proposed as contributors to healthy youth development. The Enriched Sport Activities project (http://www.esaprogram.eu) addresses the objective of the social value of sport, in particular for health, physical fitness, social inclusion, and motivation quality. This is done by implementing intervention programs for children in different development stages and/or with special needs, as well as their parents.

Family-related variables are considered one of the most important factors of physical activity engagement since parents and siblings seem to influence the choice of social and physical activities and stimulate or halt participation in sport and exercise. The model of parental involvement has contributed to an integrative rationale for research on youth sport, examining the associations between parent-child relationships and children's psychological outcomes. Based on this line of research, a study conducted by Teques and colleagues [27] has contributed to expanding the knowledge on how parent behaviors are associated with their children's achievement of elite performance in sport by exploring the nature of psychological variables.

Organized leisure-time activities represent a wide range of activities outside the regular school curriculum. A central aspect of organized leisure-time activities is organized competitive sports activities. There are sports groups and teams within the physical activity setting all around the globe, and they involve enormous numbers of participants of different ages. Additionally, it is well established in the literature that group structure, processes, and unity are important considerations for interdependent sport groups such as handball, hockey, and football teams [28]. However, group dynamics research is still under research based in this multidimensional framework of sport development. The multifaceted process of competitive sport for youth and elite athletes-training monitoring, analysis of tactical behavior, and competitive games-is another line of research that should be considered $[29,30]$.

In the physical activity and healthy lifestyle research area, the assessment and development of validated instruments and protocols are key aspects in the growing literature. Specifically, the measure of psychological variables [31], physical fitness field-based tests [32], and sport interventions programs [33] are some of the areas of research conducted by the LRQC research team.

As previously mentioned, physical inactivity is widely recognized as a risk factor for illnesses in adulthood. Thus, health-promoting interventions, including enhanced physical activity and exercise programs are able to decrease morbidity and early mortality, since they are associated with an increase 
in physical fitness, consequently resulting in higher levels of quality of life. The promotion of physical activity in a society where sport is valued and where everyone has the chance to live a healthy and active life is the unifying line of research topics in the area.

\section{Food Production and Technology/Food Behavior}

The global population is expected to reach at least 9.7 billion by the year 2050 according to a United Nations (UN) report published in 2019 [34]. Consequently, there will be an increase in food demand and agricultural activities that will have to cope with the greatest challenge of all times. The population will require nearly $70 \%$ more food in the context of a smaller food supply, less food safety, and lesser equity of the food system. Additionally, governments will have to deal with the task of being able to preserve biodiversity and the environment. The sustainable development goals established by the UN also focus on a number of critical global issues that are intimately related to the need to transition from global food systems and fossil food supply to sustainable production and consumption [35]. Specifically, Goal 2 (Zero hunger), Goal 12 (Ensure sustainable consumption and production patterns), and Goal 13 (Climate action) proposed by the UN are the ones that are consistent with the need to achieve food security, sustainable production and consumption. These are well-known issues which relate food with several diseases and food waste. But they include more broadly the questions of food security and food safety, the consequences of the new trends, new methods of food production, great diversity of distribution channels, and new eating habits. King and colleagues [36] emphasize the scale of these challenges by adding factors such as the increased aging of the population and the strong environmental constraints. The scientific area of production and food technology/food behavior at the LQRC fosters research and development on knowledge based in rural activity. We also cooperate with partners to transfer technologically innovative processes to the agri-food chain. Research conducted by the researchers at the LQRC unit aims to improve the economic, environmental, and social sustainability of rural areas, in particular the development of agricultural systems and food supply chains, with an increase in quality of life patterns in citizens. Thus, it is the priority of the LQRC researchers to work hand-in-hand with farmers and agri-food producers in establishing interactions with local, regional, and government authorities. As a consequence, the consumer will feel more empowered, food and nutrition education will increase its importance in promoting consumption and the integration of agri-food products into a healthy lifestyle. The research activities in the scientific area of food production and technology / food behavior are framed within the sustainable development of agriculture, agri-food industry, and quality of life in rural areas. These activities are in line with some of the Common Agricultural Policy general objectives proposed by the European Commission for 2021-2027, namely: i) to foster a smart, resilient and diversified agricultural sector ensuring food security; ii) to bolster environmental care; and iii) to strengthen the socio-economic fabric of rural areas.

Additionally, research on agriculture and food production answers to one of the proposed specific objectives to improve the response of EU agriculture to societal demands on food and health. This includes safe, nutritious and sustainable food, reducing food waste, as well as animal welfare [37].

Focusing on the perspective of circular economics, researchers of this scientific area have joined efforts to find better technological processes and new product development, either with raw materials discarded in the agri-food industry or by valuing the fruits and vegetables that do not meet the conditions to be sold fresh on the market, for example, due to their low caliber. The researchers also intend to enhance, requalify, and recreate traditional or local products that have fallen out of use, representing a healthy and more natural engagement with food consumption which benefits the consumers' quality of life.

New techniques, new technologies, and new products have been developed looking for convenience in distribution and consumption, creating value for the whole agriculture industry sector.

As a centralizing project, the team has been developing, since 2017, a technological procedure of interest for the industry-a pre-treatment by osmotic dehydration promoted as a complement 
to traditional drying. In addition to the valuation of low-caliber pome fruit, this process improves the organoleptic characteristics of the final product-dehydrated sliced apple and pear.

The research group also develops new spread creams with the incorporation of syrups of red fruit, peppers, mushrooms or beets in innovative food emulsions, valuing by-products of the agri-food industries. Physical-chemical and nutritional analyses were performed, and a set of microbial populations was evaluated to control microbiological stability. These new products have the advantage of not using palm oil and have the potential for application in niche markets-gourmet, diet and vegan, despite being healthy alternatives for any consumer. Beyond the commitment to the environment, these new products can be efficient alternatives to diversify and better evaluate a surplus of fruits and vegetables industrial transformation. The research team works to obtain stability, using emerging technologies, and consequently, the longer shelf life of the developed product. In the presentation to the agribusiness sector of some of the products obtained, interest in technology transfer was manifested.

In 2019, some of the researchers began a study about the changes in food behavior in Mediterranean countries. The objective is to assess the association between lifestyle factors (e.g., food habits, Mediterranean diet adherence, physical activity, sleep, socialization, nature) and subjective well-being parameters (e.g., life satisfaction, affect, fatigue, and stress perception) in consonance with the WHO, who stated that the well-being of the European population should be one of the priorities in the Health 2020 monitoring framework [38]. For this purpose, scholars from the LQRC unit intend to establish an agreement between more than eight countries of the Mediterranean Basin.

The relationship between agricultural and agri-food activities with other factors inherent to quality of life is intense. There is preliminary work that intends to relate the agricultural activity practiced in social solidarity institutions, namely kindergartens and senior residences, that may benefit from the combination of the research activity with the other scientific areas of the LQRC.

In 2020, the number and diversification of researcher skills will allow to conduct studies on the entire agri-food chain. The dissemination of knowledge and results will ensure that new insights, innovations, food production processes, and best practices will support sustainable food production and its responsible consumption.

\section{Organizational Dynamics}

Physical activity is fundamental for a healthy lifestyle $[39,40]$. Despite its importance, the proportion of those who never exercise or play sports has increased by $4 \%$ since 2009 [37]. In Europe, $40 \%$ of citizens (more than 172 million) perform physical activity at least once a week and $7 \%$ (more than 30 million) 5 times a week or more, while $14 \%$ engage in physical activity in a sports facility [41].

The need to increase the number of citizens engaging in physical activity can be tackled as a problem of adherence to sports activities, while there is a lack of research addressing sports as an opportunity to engage in massive participation in active behavior [42]. However, to increase sports practice it is mandatory to retain the people already engaging in physical activity, which is one of the main problems that sports managers deal with today [43]. The problem requires several approaches aiming to reduce dropout and increase adherence, acknowledging well-being as a priority.

Dropout represents a non-repurchase intention of the services provided, in contrast with retention which represents a customer's intention to repurchase and their willingness to recommend the service to other prospective customers [44]. Cervelló and colleagues [45] stated that dropout occurs when participation in training sessions and competitions stops. Several studies show that between $40-50 \%$ of persons joining fitness clubs leave within the first year [43]. Regular physical activity promotes and maintains health and reduces the risk of chronic diseases and premature mortality [39], contributing to the primary and secondary prevention of several chronic diseases [40].

The increase in sport participation is a problem which requires motivation assessment on why people have to participate in physical activity, which is where the opportunities for sports management and sport management researchers to contribute to health should be addressed [42]. Those opportunities 
require new approaches to exploring the factors contributing to physical activity adherence according to the models that Browning and Thomas [46] described, which have been tested most widely in health promotion literature: the Health Belief Model, the theory of planned behavior, the theory of self-efficacy, self-determination theory, the achievement goal theory, and the transtheoretical model.

The increase in quality of life and well-being during sport participation has been studied in the last years, whereby past research has used different terms such as happiness and life satisfaction when aiming to understand the way people evaluate their own lives [47]. The importance of sport as a way to improve well-being is an area being researched, in which recent studies have suggested that sports participation positively affects individual subjective well-being [48].

None of the previously described areas aiming at increasing sport participation as a way to contribute to well-being have succeeded without the optimization of sport organization processes, requiring that managers coordinate their activities effectively and efficiently. This optimization, according to Harmon [49], must be performed through an alignment of the strategy with the operations organizing and managing the employees to fulfil the organization goals.

The organizations' goals should be aligned with the attraction of new members and their retention without losing the main goal: promoting individual well-being. These multidimensional perspectives require a holistic approach in targeting sports organizations.

The development of studies to understand which factors affect the quality of life of the citizens in organizations or as individuals is fundamental. The multidisciplinarity of the factors and perspectives involved to identify areas to address new interventions or improve existing ones seems to be of value for future research. To our knowledge, there is a lack of literature related to the timings of physical activity dropout which requires a different methodological approach. Another area in which to increase our research is related to the awareness of the factors influencing sport activities adherence and dropout, and their impact on quality of life. These perspectives also require an understanding of how the organizations can be optimized to attract more people and reduce withdrawal rates. The factors contributing to happiness and life satisfaction, where sport activity is an underlying element, require that the sports organizations should develop an alignment to optimize the achievement of those objectives contributing to healthier lives.

\section{Motor Behavior}

Movement sciences refers to the body of knowledge related to the systematic and scientific study of human movement and to the factors related to the analysis, evolution, and recovery of human movement. The research emphasizes both the typical and atypical movements and on intrinsic and extrinsic constraints. The field of movement sciences has a strong multidisciplinary character with roots in functional anatomy, biomechanics, neuroscience, and anthropology. Specifically, research questions focus on understanding how sensory, perceptual, neuronal, and motor systems interact to regulate human movement and to learn how to move; thus, aiming to understand how the processes of the environment and culture influence learning and control of motor skills, with or without instruments and implements.

Movement science assumes, as an essential proposition, that human movement is seen as the visible, measurable, and evaluable expression of the continuous interaction between intrinsic and extrinsic constraints. Internationally, this scientific area is already widely disseminated and assumed, mainly in the European context; namely, in prestigious scientific reviews (e.g., Human Movement Science, Journal of Motor Control, Journal of Motor Learning and Development, Journal of Motor Behavior) and in international organizations (e.g., The International Society of Motor Control, International Motor Development Research Consortium). The main fields in this area of knowledge are: motor development, motor learning, and motor control.

Motor development, motor learning, and motor control fit into the broader designation of motor behavior [50]. The area of knowledge of motor behavior belongs to the social sciences, assuming the field of study in human behavior through the movement and the body in the context of sports culture and 
in the culture of body practices. Among these fields of knowledge, there is a high overlap of scientific content, theories and methods and the artificial separation of these fields can inhibit the understanding of contents that are transversal to them. For example, it is assumed that in any motor performance, the sources of constraints of the task made by the organism in response to the environment interact [50], whether analyzed in a more restricted time window of (socio-)motor control, in a more extended one as in (socio-)motor learning, or in a more prolonged one as in (socio-)motor skill development.

The field of motor control concerns the study of how the neuromuscular system works to activate and coordinate muscles and limbs involved in the motor provision of motor skills already acquired or new [51]. It has historical roots both in currents of motor programming, as in Fitts's Law that establishes the relationship between speed, precision, and time of movement; as well as in currents of perceptual-motor interaction, such as the Bernstein [52] principle of motor variability that recognizes the intrinsic variability of movement.

The field of motor learning concerns the study of the acquisition of motor skills, and the essential role of practice, experience, and the organization of the practice context, namely: instruction, feedback, demonstration, variability, degree of difficulty, repetition, and transfer, among others. Motor learning is a process of complexification of the motor system, enhancing adaptation, efficacy in a relatively stable and permanent new state. This process is present at all levels of motor experience, such as in the recovery of previously lost motor domain, and it is a process that has no end $[53,54]$.

The field of motor development examines the observable changes in motor behavior throughout life, requiring articulation with other areas of knowledge, from biology to anthropology. Currently, active perceptual exploration, the influence of extrinsic constraints, and the self-organizing properties of the motor system are the main focus of research; especially since this approach allows us to admit that complex systems can generate change and bring about new patterns and forms of behaviors due to the complementarity and mutuality between body and environment.

Movement is certainly one of the main catalyst items within LQRC. It plays a central role in several subject areas and indicators of quality of life that we most stress in our research centre. In the multidisciplinary unit of the LQRC, body movement literacy evokes questions about its role and function in social and cultural intervention, such as health and education. These social areas are very important for the quality of life of persons and communities. Looking to movement as the trigger for infant development, as the core of non-verbal communication, the contribution of movement science can help to understand how infant motor stimulation allows the remediation of developmental problems. It also helps us to understand how a child learns words through gestures, how a health professional incorporates and uses a surgery tool, how youngsters appropriate social roles, how an animal or an athlete recover from an injury, how physical balance helps a team or a community to share common values or to face social and cultural problems, how the learning of motor abilities sustains adherence to exercise and sport, how play and sport rules can help to defend the rights of girls and women.

Such contribution is evident in the scientific production made by the LQRC body of researchers specializing in these areas of knowledge, studying topics as varied as: motor control and development problems [55,56]; unintentional socio-motor synchronization [57]; perceptual motor development, gesture and the development of spoken language [58]; sports and gender rules [59]; unconventional therapeutic body techniques and regulation of vital signs [60-62]; haptic perception of functional properties of instruments in children and the elderly [63]; visual perception and motor control [64]; visual perception and navigation [65,66]; task constraints and motor control [67,68]; social affordances and motor development [69]; degrees of freedom of sports instruments and motor learning [70]; adaptive motor abilities in infants; learning specific socio-motor skills [71]; maturation and sports selection [72]; aging and motor control of specific motor abilities [73,74]; and kinesiology of sports injury [75]. 


\section{Individual and Community Health}

Health and quality of life are two concepts that are characterized by the uniqueness with which each individual approaches them as long as they have the capacity to make informed and appropriate decisions for their intervention, or as a partner in the care process assuming an individual, family and community dimension.

The approach to health throughout the life cycle has been an orientation for the development of research, marked by the mobilization of theoretical concepts that allow, identify, understand, and plan the intervention in the field of health needs, identifiable at different levels of relationship with the community.

The models referred to are located in the field of interdisciplinary mobilizing according to the level of intervention, and mobilizing orientations from Antonovsky's [76] salutogenic model, Bronfenbrenner and Morris's [77] bioecological model, the health promotion model proposed by Pender [78], and centrality of care $[79,80]$, an integrated perspective between health promotion and empowerment in the affirmation of health literacy.

This perspective allows individuals and the community to deepen their training to maintain a state of autonomy and independence that supports self-care, in the cultural diversity inherent to the individual, family and community.

The health research agenda is still marked by the relevance that public policies represent in public health policies, in which smart governance is increasingly invested in "for health defines how governments approach governance for health challenges strategically in five dimensions, through: collaboration; engagement; a mixture of regulation and persuasion; independent agencies and expert bodies; and adaptive policies, resilient structures and foresight" [81].

It is relevant to mobilize the principles of good governance, of which we highlight participation, transparency, and consensus, in a perspective of sustainable development, namely through Goal 3: ensure healthy lives and promote well-being for all at all ages, essential to quality of life.

In this sense, we mobilized the research that has been developed by researchers from the Health Indicators Monitoring Unit (UMIS), essentially in the last five years, emphasizing the importance of knowledge, focusing mainly on three concepts: health promotion, empowerment and literacy for Health. Figueiredo and Amendoeira [82] contributed to the knowledge and relevance of health promotion in nursing curricula, in the first and second cycle. The contribution of this investigation is essentially relevant due to the clarification it brought within the scope of the salutogenic [76] and bioecological [77] models, in the understanding of the transition from a behavioral model of health promotion [78], for a perspective more focused on diversity and uniqueness, with recognition from professionals, regarding the status of the person, family and community in applied research [83].

The research developed in the LQRC takes place in a perspective of integration between the activities of extension to the community and, out of the interinstitutional cooperation, emerging research projects which emphasize the promotion of health as support to a type of decision-making based on informed choices, which promote quality of life from the individual to the community domain, in a clear assumption of a subjective nature in the eyes of health professionals. They need to operationalize the transition from a normalization of interventions to an attitude open to citizen, family and community participation, in the process of individual and community empowerment [83].

The bioecological model [77], by the systemic approach that it develops, allows us to identify four dimensions (people, contexts, processes, and time) that substantially reveal the importance of health promotion in quality of life, in a concept that WHO names Healthy Aging: "Healthy Aging is about creating the environments and opportunities that enable people to be and do what they value throughout their lives" [84].

It becomes relevant that in this domain, "The aging population brings many challenges surrounding quality of life for older people and their careers, as well as impacts on the labor market. These challenges need to be addressed now if we are to ensure that we can continue to live healthy, active, and independent lives into our old age" [84]. 
Amendoeira and colleagues [85] consider in this regard that "the social determinants of health acquire in this domain of research and reflection on practices, the meaning that becomes necessary to decode by reference to the contexts where people are born, live and build themselves as citizens capable of building health".

This approach can be mediated by theories in the field of health promotion as an essential concept in this conception, in which Murdaugh, Parsons and Pender [78] go further when they affirm that not all people who do not have a disease are equally healthy, adding that, for many, it is more the "ways of life" that integrate elements of individual and collective action in the construction of health determinants and not the "pathological situations" that define health. Currently and according to Figueiredo and Amendoeira [82], the guidelines set out in the Ottawa Charter have come to show a new way of looking at health with an emphasis on health promotion. Whitehead [86] proposed a review of nursing curricula to identify and measure the nature and extent of health promotion in all nursing disciplines and obstetrics, at the level of undergraduate and graduate courses. Mcllfatrick [87] refers to the importance of including health promotion in nursing curricula with interventions on health determinants [88].

Continuing this perspective, it is important to take a theoretical approach that considers health and disease as entities that are increasingly studied from a salutogenic perspective with a focus on promoting health and deepening this and other strategies within the scope of health literacy.

It is in this sense that the salutogenic model allows us to assume the paradigm where disease is not the opposite of health, insofar as it is possible to work from the perspective of health determinants, in an intrinsic relationship with the social, cultural, and economic dimensions, assuming the recommendations by $\mathrm{WHO}$, in the domain previously referred to as Healthy Aging.

The research carried out by the team in the individual and community health area has been organized with an emphasis on addressing the modifiable factors (food and harmful consumption), particularly directed at pregnant women [89], and adolescents and young people 3rd cycle students [90] in informed and informed co-construction, in participation to ensure quality of life of the individual and in the community.

Intervention centered on people, families and the community with the purpose of training, at all levels of decision-making, is consistent with the expression of the interests and values of the stakeholders in the care process inherent to training for, in the domain of the individual, becoming what can be considered as a therapeutic self-care agent [80] in order to empower families and the community as active partners in the referred care process.

It is to the extent that the visibility of this training occurs that we can also speak of health literacy [91]. At the first International Congress on Health Literacyz in 2019, there was an opportunity for intense sharing based on the results of research developed in several countries in Europe and Brazil, allowing the knowledge produced in this field, constituting guidance for extending it to new contexts and groups of participants, to be mobilized for the operationalization of the recommendations for the research to be developed in the scope of health literacy.

We believe that this is the matrix that supports the realization of the study of the healthy aging process, starting with pregnant women, children and young people, adults in active life, and the elderly, constituting the challenge of the individual and community health area in the next three years within the scope of LQRC, assuming the relevance of quality of life for people throughout their lives.

\section{Conclusions}

The authors agree and understand that quality of life research is on the agenda of the world organizations related to scientific research and human development. This scope of research occurs in different scenarios for the success of our society, either through projects based in laboratory environments, in development projects, and in social and professional intervention.

Throughout this paper, the authors hope to have delivered a clear picture of how possible (and fundamental) it is to group (six) different areas for a common goal. The conceptual framework of 
LQRC goes around three strategic axes. In fact, education, physical activity and feeding gather around themselves the six areas that cooperate for positive outcomes in quality of life research. We would like to stress that these areas do not exhaust all the factors, areas or items related to quality of life. They consubstantiate and are in line with the most effective resources of LQRC and the consortium of higher education institutes that supports it. This is the approach we have reached after several years of existence and the one that assures that greater and better synergies amongst LQRC researchers can emerge. We are very close and connected to the binomial perspective of quality of life and well-being. That is why we focus our research efforts, in a broad sense, on individual and community health and quality of life of people and populations. This means a strategy is necessary to deepen the health literacy of citizens.

The development of an interdisciplinary approach, with contributions from the areas of education, physical activity, agriculture and food, organizations, motor behavior, and individual and community health, seems to suit the development of research projects with interconnections of variables and paradigms when studying quality of life.

We believe that there is a real challenge for scientific research, since multidisciplinary paradigms are the foundation of our collective organization, with a view to the systemic influence of psychological, physiological, and emotional variables related to quality of life. It is a dialectical problem in the sense of the evolution of research on quality of life fulfilling current needs and improvement of citizens' lives.

Author Contributions: All authors have done work on conceptualization, methodology, investigation, resources, writing—original draft preparation, writing—review and editing, supervision, project administration, and funding acquisition. All authors have read and agreed to the published version of the manuscript.

Funding: This research was funded by the FUNDAÇÃO PARA A CIÊNCIA E TECNOLOGIA, grant number UIDB/04748/2020.

Conflicts of Interest: The authors declare no conflict of interest. The funders had no role in the design of the study; in the collection, analyses, or interpretation of data; in the writing of the manuscript, or in the decision to publish the results.

\section{References}

1. World Health Organization. Men, Ageing and Health: Achieving Health Across the Span; Unit Ageing and Life Course; World Health Organization-WHO: Geneva, Switzerland, 2001.

2. Pereira, É.; Teixeira, C.; Santos, A. Qualidade de vida: Abordagens, conceitos e avaliação. Rev. Bras. Educ. Fís. Esporte 2012, 26, 241-250. [CrossRef]

3. WHOQOL. Position paper from the World Health Organization. Soc. Sci. Med. 1995, 41, 1403-1409. [CrossRef]

4. UNHDP. United Nations Human Development Report 2003; Oxford University Press Inc.: New York, NY, USA, 2003.

5. Haggerty, M.; Cummins, R.; Ferriss, A.; Land, K.; Michalos, A.; Peterson, M.; Sharpe, A.; Sirgy, J.; Vogel, J. Quality of life indexes for national policy: Review and agenda for research. Soc. Indica Res. 2001, 55, 1-96. [CrossRef]

6. European Union. Final Report of the Expert Group on Quality of Life Indicators; Publications Office of the European Union: Luxembourg, 2017. [CrossRef]

7. Evangelista, L.; Rasmusson, K.; Laramee, A.; Barr, J.; Ammon, S.; Dunbar, S.; Ziesche, S.; Patterson, J.H.; Yancy, C. Health Literacy and the Patient with Heart Failure-Implications for Patient Care and Research: A Consensus Statement of the Heart Failure Society of America. J. Card. Fail. 2010, 16, 9-16. [CrossRef]

8. Baker, D.; Asch, S.; Keesey, J.; Brown, J.; Chan, K.; Joyce, G.; Keeler, E. Differences in Education, Knowledge, Self-Management Activities, and Health Outcomes for Patients With Heart Failure Cared for Under the Chronic Disease Model: The Improving Chronic Illness Care Evaluation. J. Card. Fail. 2005, 11, 405-413. [CrossRef]

9. Nesbitt, T.; Doctorvaladan, S.; Southard, J.A.; Singh, S.; Fekete, A.; Marie, K.; Moser, D.K.; Pelter, M.M.; Robinson, S.; Wilson, M.D.; et al. Correlates of quality of life in rural patients with heart failure. Circ. Heart Fail. 2014, 7, 882-887. [CrossRef] 
10. Skevington, S. Qualities of life, educational level and human development: An international investigation of health. Soc. Psychiatr. Epidemiol. 2010, 45, 999-1009. [CrossRef]

11. Lai, C.-L.; Hwang, G.-J. A self-regulated flipped classroom approach to improving students' learning performance in a mathematics course. Comput. Educ. 2016, 100, 126-140. [CrossRef]

12. Akçayır, G.; Akçayır, M. The flipped classroom: A review of its advantages and challenges. Comput. Educ. 2018, 126, 334-345. [CrossRef]

13. Tu, J.-C.; Liu, L.-X.; Wu, K.-Y. Study on the Learning Effectiveness of Stanford Design Thinking in Integrated Design Education. Sustainability 2018, 10, 2649. [CrossRef]

14. Koh, J.H.L.; Chai, C.S.; Wong, B.; Hong, H.-Y. Design Thinking for Education: Conceptions and Applications in Teaching and Learning; Springer: Singapore, 2015. [CrossRef]

15. Yew, E.H.J.; Goh, K. Problem-Based Learning: An Overview of its Process and Impact on Learning. Health Prof. Educ. 2016, 2, 75-79. [CrossRef]

16. Strobel, J.; van Barneveld, A. When is PBL more effective? A meta-synthesis of meta-analyses comparing PBL to conventional classrooms. Interdiscip. J. Problem-Based Learn. 2009, 3, 44-58. [CrossRef]

17. Jakicic, J.; Rogers, R. Gamification and social incentives increase physical activity. Nat. Rev. Endocrinol. 2020, 16, 10-12. [CrossRef] [PubMed]

18. Mo, D.; Xiang, M.; Luo, M.; Dong, Y.; Fang, Y.; Zhang, S.; Zhang, Z.; Liang, H. Using Gamification and Social Incentives to Increase Physical Activity and Related Social Cognition among Undergraduate Students in Shanghai, China. Int. J. Environ. Res. Public Health 2019, 16, 858. [CrossRef]

19. Woodcock, J.; Franco, O.H.; Orsini, N.; Roberts, I. Non-vigorous physical activity and all-cause mortality: Systematic review and meta-analysis of cohort studies. Int. J. Epidemiol. 2011, 40, 121-138. [CrossRef]

20. Hupin, D.; Roche, F.; Gremeaux, V. Even a low-dose of moderate-to-vigorous physical activity reduces mortality by $22 \%$ in adults aged $\geq 60$ years: A systematic review and meta-analysis. Br. J. Sports Med. 2015, 49, 1262-1267. [CrossRef]

21. Vieira, I.; Ramos, L.; Simões, V.; Franco, S.; Esteves, D. Qualidade de Vida dos Profissionais de Fitness-Estudo Piloto. J. Sport Pedagog. Res. 2019, 5, 6.

22. Ramos, L.; Vieira, I.; Simões, V.; Franco, S.; Esteves, D. Fitness Professionals: Narrative Review. J. Hum. Sport Exerc. 2019, 3, 1311-1314. [CrossRef]

23. Sawyer, S.; Afifi, R.; Bearinger, L.; Blakemore, S.; Dick, B.; Ezeh, A.; Patton, G. Adolescence: A foundation for future health. Lancet 2012, 379, 1630-1640. [CrossRef]

24. Cid, L.; Pires, A.; Borrego, C.; Duarte-Mendes, P.; Teixeira, D.; Moutão, J.; Monteiro, D. Motivational determinants of physical education grades and the intention to practice sport in the future. PLOS ONE 2019, 14, e0217218. [CrossRef]

25. Gómez-López, M.; Borrego, C.; Marques da Silva, C.; Granero-Gallegos, A.; González-Hernández, J. Effects of Motivational Climate on Fear of Failure and Anxiety in Teen Handball Players. Int. J. Environ. Res. Public Health 2020, 17, 592. [CrossRef] [PubMed]

26. Huéscar, E.; Moreno-Murcia, J.; Cid, L.; Monteiro, D.; Rodrigues, F. Passion or Perseverance? The Effect of Perceived Autonomy Support and Grit on Academic Performance in College Students. Int. J. Environ. Res. Public Health 2020, 17, 2143. [CrossRef] [PubMed]

27. Teques, P.; Calmeiro, L.; Rosado, A.; Silva, C.; Serpa, S. Perceptions of Parenting Practices and Psychological Variables of Elite and Sub-Elite Youth Athletes. Front. Psychol. 2019, 10. [CrossRef] [PubMed]

28. Eys, M.; Brawley, L. Reflections on cohesion research with sport and exercise groups. Soc. Personal. Psychol. Compass 2018, 12, e12379. [CrossRef]

29. Matos, R.; Amaro, N.; Pollard, R. How best to quantify home advantage in team sports: An investigation involving male senior handball leagues in Portugal and Spain. Rev. Int. Cienc. Deporte 2020, 16, 12-23. [CrossRef]

30. Oliveira, R.; Brito, J.; Martins, A.; Mendes, B.; Marinho, D.; Ferraz, R.; Marques, M. In-season internal and external training load quantification of an elite European soccer team. PLoS ONE 2019, 14, e0209393. [CrossRef]

31. Antunes, R.; Couto, N.; Vitorino, A.; Monteiro, D.; Marinho, D.; Cid, L. Physical activity and affect of the elderly: Contribution to the validation of the Positive and Negative Affect Shedule (PANAS) in the Portuguese population. J. Hum. Sport Exerc. 2019, 15. [CrossRef] 
32. Tabacchi, G.; Sánche, G.; Sahin, F.; Kizilyalli, M.; Genchi, R.; Basile, M.; Kirkar, M. Field-Based Tests for the Assessment of Physical Fitness in Children and Adolescents Practicing Sport: A Systematic Review within the ESA Program. Sustainability 2019, 7187. [CrossRef]

33. Scifo, L.; Chicau Borrego, C.; Monteiro, D.; Matosic, D.; Feka, K.; Bianco, A.; Alesi, M. Sport Intervention Programs (SIPs) to Improve Health and Social Inclusion in People with Intellectual Disabilities: A Systematic Review. J. Funct. Morphol. Kinesiol. 2019, 4, 57. [CrossRef]

34. United Nations (UN); Department of Economic and Social Affairs Population Division. World Population Prospects 2019: Highlights; United Nations Publication (ST/ESA/SER.A/423); United Nations: New York, NY, USA, 2019; Available online: https://population.un.org/wpp/Publications/Files/WPP2019_Highlights.pdf (accessed on 4 May 2020).

35. Holden, N.; White, E.; Lange, M.; Oldfield, T. Review of the sustainability of food systems and transition using the Internet of Food. NPJ Sci. Food 2018, 2, 1-27. [CrossRef]

36. King, T.; Cole, M.; Farber, J.; Eisenbrand, G.; Zabaras, D.; Fox, E.; Hill, J. Food safety for food security: Relationship between global megatrends and developments in food safety. Trends Food Sci. Technol. 2017. [CrossRef]

37. Lamkin, N.; Stolze, M.; Meredith, S.; de Porras, M.; Haller, L.; Mészáros, D. Using Eco-Schemes in the New Cap a Guide for Managing; IFOAM EU: Brussels, Belgium; FIBL: Brussels, Belgium; IEEP: Brussels, Belgium, 2020; Available online: https://orgprints.org/37227/1/lampkin-etal-2020-IFOAM-Eco-schemes-guide-final.pdf (accessed on 5 May 2020).

38. World Health Organization. Targets and Beyond-Reaching New Frontiers in Evidence. 2015. Available online: http://www.euro.who.int/_data/assets/pdf_file/0006/288645/European-health-report-2015-full-booken.pdf (accessed on 5 May 2020).

39. Haskell, W.; Lee, I.-M.; Pate, R.; Powell, K.; Blair, S.; Franklin, B.; Macera, C.A.; Heath, G.W.; Thompson, P.D.; Bauman, A. Physical Activity and Public Health: Updated Recommendation for Adults From the American College of Sports Medicine and the American Heart Association. Circulation 2007, 116, 1081-1093. [CrossRef] [PubMed]

40. Warburton, D.; Nicol, C.; Bredin, S. Health benefits of physical activity: The evidence. Cmaj 2006, 174, 801-809. [CrossRef] [PubMed]

41. European Commission. Special Eurobarometer 472 "Sport and Physical Activity"; European Commission: Brussels, Belgium, 2020.

42. Henderson, K. A paradox of sport management and physical activity interventions. Sport Manag. Rev. 2009, 12,57-65. [CrossRef]

43. MacIntosh, E.; Law, B. Should I stay or should I go? Exploring the decision to join, maintain, or cancel a fitness membership. Manag. Sport Leis. 2015, 20, 191-210. [CrossRef]

44. Howat, G.; Crilley, G. Customer Service Quality, Satisfaction, and Operational Performance: A proposed model for Australian public aquatic centres. Ann. Leis. Res. 2007, 10, 168-195. [CrossRef]

45. Cervelló, E.; Escartí, A.; Guzmán, J. Youth sport dropout from the achievement goal theory. Psicothema 2007, 19, 65-71.

46. Browning, C.; Thomas, S. Behavioural Change: An Evidence-Based Handbook for Social and Public Health; Elsevier Health Sciences: Amsterdam, The Netherlands, 2006.

47. Diener, E.; Diener, C.; Choi, H.; Oishi, S. Revisiting "Most People Are Happy"-And Discovering When They Are Not. Perspect. Psychol. Sci. 2018, 13, 166-170. [CrossRef]

48. Silva, A.; Monteiro, D.; Sobreiro, P. Effects of sports participation and the perceived value of elite sport on subjective well-being. Sport Soc. 2019, 1-22. [CrossRef]

49. Harmon, P. The Scope and Evolution of Business Process Management. In Handbook on Business Process Management; International Handbooks on Information Systems; Springer: Berlin, Germany, 2010; Volume 1, pp. 37-81. [CrossRef]

50. Newell, K.; Jordan, K. Task constraints and movement organization: A common language. In Ecological Task Analysis and Movement; Davis, W.E., Broadhead, G.D., Eds.; Human Kinetics: Champaign, IL, USA, 2007; pp. 5-23.

51. Shumway-Cook, A.; Woollacott, M. Motor Control: Theory and Practical Applications, 2nd ed.; Lippincott Williams \& Wilkins: Philadelphia, PA, USA, 2001.

52. Bernstein, N. The Co-Ordination and Regulation of Movements; Pergamnon Press: Oxford, UK, 1967. 
53. Rose, D.; Christina, R. A Multilevel Approach to the Study of Motor Control and Learning, 2nd ed.; Pearson Education, Inc.: San Francisco, CA, USA, 2006.

54. Magill, R.; Anderson, D. Motor Learning and Control: Concepts and Applications, 11th eds.; Mac McGraw-Hill Education: New York, NY, USA, 2007.

55. Matias, B.; Nunes, M.; Neves, P.; Rodrigues, S.; Seabra, A.; Catela, D. Estudo piloto sobre equilíbrio dinâmico em crianças portadoras de trissomia 21. In Estudos em Desenvolvimento Motor da Criança XIV; O'Hara, K., Travassos, B., Lourenço, C., Eds.; UBI Edições: Covilhã, Portugal, 2019; pp. 271-276. ISBN 978-989-654-605-2.

56. Catela, D.; Ferreira, M.; Branco, M. Preserving Motor Abilities Through Functional Stimulation in Institutionalized Elderly with Probable Alzheimer's Disease. J. Funct. Neurol. Rehabil. Ergon. 2017, 7, 43-46.

57. Mercê, C.; Branco, M.; Catela, D. Recurrence Analysis of Non-Intentional Synchronization in Children during Tap Side of Aerobics. In Studies in Perception and Action XII: Seventeenth International Conference on Perception and Action; Davis, T., Passos, P., Dicks, M., Weast-Knapp, J., Eds.; Psychology Press, Taylor \& Francis: New York, NY, USA, 2014; pp. 33-37. ISBN 978-1-84872-525-6.

58. Catela, D.; Silva, C.; Reis, J.; Seabra, A. An Exploratory Behavioral Study in Children of Four Years of Age on the Hypothesis of a Two Streams System in Touch Perception and Language Development. Psychol. Res. 2018, 8, 567-571. [CrossRef]

59. Catela, D.; Seabra, A. Gender in Sport: The Height of the Hurdles. In Social Determinants of Sports Activity; Seabra, D., Kosiewicz, J., Eds.; Universidade Fernando Pessoa: Porto, Portugal, 2015; pp. 101-108. ISBN 978-989-643-132-7.

60. Catela, D.; Mercê, C. Diaphragmatic Breathing Technique an Example of Motor Literacy for Health in Elderly with Isolated Systolic Hypertension. Eur. J. Public Health 2019, 29, ckz096.007. [CrossRef]

61. Catela, D.; Seabra, A.; Mercê, C.; Branco, M. Effect of Slow Abdominal Breathing Technique on Heart Rate Variability in Male Smokers. J. Yoga Phys. Ther. Rehabil. 2018, 2, 1-8. [CrossRef]

62. Catela, D.; Alves, S.; Piscalho, I. Respiratory Control Technique and Heart Rate Variability in a Child with Attention Deficit and Hyperactivity Disorder: A Case Study. Psychol. Res. 2018, 8, 512-521. [CrossRef]

63. Ferreira, D.; Catela, D. Haptic Perception of Physical and Functional Properties of Table Tennis and Badminton Rackets in Children and Elderly. Psychol. Res. 2019, 9, 329-334. [CrossRef]

64. Matos, R.; Amaro, N.; Coelho, L.; Cruz, J.; Gonçalves, R.; Morouço, P. Effect of different visual constraints on standing long jump' intra-variability. Motricidade 2019, 15, 100.

65. Matos, R.; Amaro, N.; Coelho, L.; Cruz, J.; Gonçalves, R.; Morouço, P.; Barroso, M. Elite Orienteering athletes have a better Useful Field of Vision than non-elite. Motricidade 2019, 15, 90.

66. Catela, D.; Barroso, M.; Seabra, A. Orienteering using realistic map (colored aerial photography) with kindergarten children. Rev. UIIPS Unidade Investig. Inst. Politéc. Santarém 2019, 7, 132-135.

67. Coelho, L.; Gonçalves, R.; Amaro, N.; Cruz, J.; Morouço, P.; Matos, R. Between Backward \& Forward Dynamic Balance. Motricidade 2019, 15, 98.

68. Santos, C.; Mercê, C.; Branco, M.; Catela, D. Recurrence Analysis of Interjoint Coordination in Children during Volleyball Practice Task Constraints. In Studies in Perception and Action XII: Seventeenth International Conference on Perception and Action; Davis, T., Passos, P., Dicks, M., Weast-Knapp, J., Eds.; Psychology Press, Taylor \& Francis: New York, NY, USA, 2014; pp. 134-138. ISBN 978-1-84872-525-6.

69. Rezendes, P.; Catela, D. Affordances motoras em contexto familiar, de crianças dos 18 aos 42 meses, do concelho das Caldas da Rainha. In Estudos em Desenvolvimento Motor da Criança XIV; O’Hara, K., Travassos, B., Lourenço, C., Eds.; UBI Edições: Covilhã, Portugal, 2019; pp. 131-136. ISBN 978-989-654-605-2.

70. Mercê, C.; Catela, D.; Branco, M.; Cordovil, R. Serão as bicicletas sem pedais melhores para aprender a andar de bicicleta? In Estudos em Desenvolvimento Motor da Criança XIV; O’Hara, K., Travassos, B., Lourenço, C., Eds.; UBI Edições: Covilhã, Portugal, 2019; ISBN 978-989-654-605-2.

71. Barros, N.; Branco, M.; Catela, D. The basic foundations of capoeira learning: Preliminary evaluation of a formative program. Rev. Artes Marciales Asiáticas 2019, 14, 9-20. [CrossRef]

72. Branco, M.; VencesBrito, A.; Seabra, A.; Mercê, C.; Rodrigues-Ferreira, M.; Milheiro, V.; Catela, D. Exploratory study on maturation and competition level in young karate practitioners. Rev. Artes Marciales Asiáticas 2019, 14, 1-8. [CrossRef] 
73. Branco, M.A.C.; VencesBrito, A.M.V.; Rodrigues-Ferreira, M.A.; Branco, G.A.C.; Polak, E.; Cynarski, W.J.; Jacek, W. Effect of Aging on the Lower Limb Kinematics in Karate Practitioners: Comparing Athletes and Their Senseis. J. Healthc. Eng. 2019, 2672185, 1-6. [CrossRef] [PubMed]

74. Brito, A.; Ferreira, M.; Branco, M.A. The effects of aging on electromechanical delay: A comparison between karate athletes and non-athletes. Int. J. Sports Sci. Med. 2017, 1, 17-23.

75. VencesBrito, A.M.; Rodrigues-Ferreira, M.A.; Castro, M.A.; Polak, E.; Valente, E.J.; Romero, F.; Figueiredo, A. Sport injuries in Portuguese female and male karateka: A retrospective study. Ido Movement for Culture. J. Martial Arts Anthropol. 2019, 19, 51-57. [CrossRef]

76. Bengt, L.; Eriksson, M. Contextualizing salutogenesis and Antonovsky in public health development. Health Promot. Int. 2006, 21, 238-244. [CrossRef]

77. Bronfenbrenner, U.; Morris, P. The bioecological model of human development. In Handbook of Child Psychology, 1: Theoretical Models of Human Development, 6th ed.; Damon, W., Lerner, R.M., Eds.; John Wiley: New York, NY, USA, 2006; pp. 793-828.

78. Murdaugh, C.L.; Parsons, M.A.; Pender, N.J. Health Promotion in Nursing Practice; Pearson Education: North York, ON, Canada, 2018.

79. McCance, T.; McCormack, B.; Dewing, J. An Exploration of Person Centredness in Practice. Online J. Issues Nurs. 2011, 16, 2.

80. Ferreira, R.; Amendoeira, J. Adaptação e validação do instrumento "Patient Centered-Care" para a cultura portuguesa. Rev. Uiips 2020, 8, 238-245. [CrossRef]

81. Kickbusch, I. Global health diplomacy: How foreign policy can influence health. Br. Med. J. 2011, 342 , d3154. [CrossRef]

82. Figueiredo, M.; Amendoeira, J. Intervenção contextualizada no domínio da promoção da saúde. Rev. Uiips Unidade Investig. Inst. Politéc. Santarém 2018, 6, 62-68.

83. Edgberg, M.; Krieger, L. Recontextualizing the social norms construct as applied to health promotion. SSM-Popul. Health 2020, 10, 1-9. [CrossRef]

84. World Health Organization. Ageing and Life-Course.What is Healthy Ageing? 2015. Available online: https://www.who.int/ageing/healthy-ageing/en/ (accessed on 9 May 2020).

85. Amendoeira, J. Determinantes Sociais de Saúde e Compreensão dos Indicadores de Saúde Numa População Concreta; FCSH_UN: Lisbon, Portugal, 2013; p. 8. ISBN 978-989-20-4086-8.

86. Whitehead, D. Reviewing health promotion in nursing education. Nurse Educ. Today 2006, 27, $225-237$. [CrossRef] [PubMed]

87. Mcilfatrick, S. The future of nursing education: Characterized by paradoxes. Nurse Educ. Today 2004, 24, 79-83. [CrossRef]

88. Loureiro, I.; Miranda, N. Promover a Saúde: Dos Fundamentos à Ação; Edições Almedina: Coimbra, Portugal, 2010.

89. André, M.; Cândido, A.; Santiago, C.; Cruz, O.; Carreira, T.; Amendoeira, J. Consumo de tabaco na mulher grávida: Revisão sistemática da literatura. Rev. Port. Enferm. Saúde Ment. 2015, 2, 113-118.

90. Godinho, A.; Amendoeira, J.; André, C. Prevenção do consumo de tabaco nos alunos do 3 ciclo-Perspetiva de uma estudante de enfermagem num projeto de investigação. Rev. Uiips 2018, 6, 69-79. [CrossRef]

91. Dias, H.; Amendoeira, J.; Spínola, A.; Figueiredo, M.; Godinho, C.; André, C.; Duarte, J.; Pintor, M.; Ferreira, M. Impact evaluation of Literacy on Health in school from the third cycle of basic education: A Scoping Review. Rev. UIIPS 2020, 8, 151-160. [CrossRef]

(C) 2020 by the authors. Licensee MDPI, Basel, Switzerland. This article is an open access article distributed under the terms and conditions of the Creative Commons Attribution (CC BY) license (http://creativecommons.org/licenses/by/4.0/). 